borhood of equilibrium, e.g. phase transitions, can however be formally described in a similar way mathematically; see H. Haken, A. Wunderlin: Dic Selbststrukturierung der Materie, Vieweg, Braunschweig 1991. In our view thicroscopic structure formation (self-organization) under the influence of a primarily formed matrix (as in the case of 3[3]) and such that proceed via weak interactions with an external matrix have probably had importance in prebiotic elementary processes (formation of biopolymers) (cf. also the definitions "matrix" and "template" in O.A. Neumüller Römpps Chemie-Lexikon, Franckh'sche Verlagshandlung, Stuttgart 1985 and 1988, p. 2510 and 4152, respectively).

[14] A further future aspect emerges from the fact that in 1 and 2 not all positions in the two equivalent layers neighboring the polar $\left\{\mathrm{V}_{3} \mathrm{O}_{7}\right\}$ units are occupied, so that other units can also be encapsulated in the cluster shells. For example, in the cluster shell of 2 also a disordered $\mathrm{NO}_{3}^{-}$ion can occur with one $\mathrm{NO}$ moiety replacing the $\mathrm{N}(\mathrm{N}) \mathrm{N}$ one: A. Müller, R. Rohlfing. unpublished results.

\section{Synthesis and Structure of the First Tellurium(III) Radical Cation**}

By Már Björgvinsson, Thorsten Heinze, Herbert W. Roesky, * Frank Pauer, Dietmar Stalke, and George M. Sheldrick*

\section{Dedicated to Professor Karl Heinz Büchel} on the occasion of his $60 \mathrm{th}$ birthday

Although compounds with tellurium-nitrogen bonds have been used for some time in organic synthesis, ${ }^{[1]}$ it is only in the last few years that they have been unambiguously structurally characterized. ${ }^{[2-12]}$ Our interest in $\mathrm{Te}-\mathrm{N}$ compounds was particularly stimulated by the isolation of the novel tricyclic tellurium nitride (ClTeNSN) ${ }_{3} \mathrm{~N} \cdot 3 \mathrm{DMF}^{\left[{ }^{[0]}\right.}$ In general, however, suitable stable precursors for the preparation of new $\mathrm{Te}-\mathrm{N}$ compounds have been lacking. Recently, we prepared $\mathrm{Te}\left(\mathrm{N}\left(\mathrm{SiMe}_{3}\right)_{2}\right)_{2}(\mathbf{1})$ in relatively good yields. ${ }^{[12]}$ In our study of the coordination properties of 1 toward silver cations, we have isolated and structurally characterized the $\mathrm{AsF}_{6}^{-}$salt of the first $\mathrm{Te}^{\mathrm{III}}$ radical cation, $\left[\mathrm{Te}\left(\mathrm{N}\left(\mathrm{SiMe}_{3}\right)_{2}\right)_{2}\right]^{++}\left(2^{+}{ }^{+}\right)$.

A dark blue solution of $\mathbf{3}$ was formed when a cold mixture $\left(-78^{\circ} \mathrm{C}\right)$ of 1 and $\mathrm{Ag}^{+} \mathrm{AsF}_{6}^{-}$in $\mathrm{CH}_{2} \mathrm{Cl}_{2}$ was allowed to

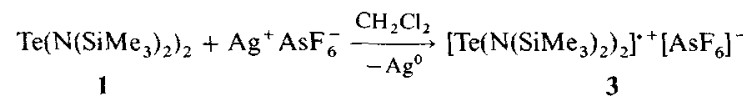

warm to room temperature [Eq. (a)]. Large crystalline blocks of $\mathbf{3}$ were isolated and its crystal structure was determined by low-temperature X-ray crystallography. ${ }^{[3]}$ The crystals of 3 consist of monomer $2^{*+}$ coordinated by two $\mathrm{AsF}_{6}^{-}$anions; thus, chains of alternating cations and anions are formed (Fig. 1).

The average Te- $\mathrm{N}$ distance of $\mathbf{2}^{+}(196.6(4) \mathrm{pm})$ is $8 \mathrm{pm}$ shorter than that of its neutral analogue $1,{ }^{[12]}$ indicating some multiple-bond character. Furthermore, the $\mathrm{Si}-\mathrm{N}$ distances are longer, the average $\mathrm{Si}-\mathrm{N}-\mathrm{Te}$ bond angle is larger, the average $\mathrm{Si}-\mathrm{N}-\mathrm{Si}$ bond angle is smaller, and the pyramid formed from the N, Si, Si, and Te atoms is flatter than in $\mathbf{1}$. These findings correlate well with the model of enhanced

[*] Prof. Dr. H. W. Roesky, Prof. G. M. Sheldrick, Dr. M. Björgvinsson, Dipl.-Chem. T. Heinze, Dr. F. Pauer, Dr. D. Stalke Institut für Anorganische Chemie der Universität Tammannstrasse 4, W-3400 Göttingen (FRG)

$\left[{ }^{* *}\right]$ This work was supported by the Deutsche Forschungsgemeinschaft (Leibniz-Programm), the Fonds der Chemischen Industrie, and the Alexander von Humboldt Foundation (award of a fellowship to $M . B$ ). We wish to thank Dr. D. Marsh and B. Angerstein at the Max-Planck-Institut für Biophysikalische Chemie, Göttingen, for measuring the ESR spectra. back-bonding of nitrogen-atom lone pairs to the positively charged tellurium atom of $\mathbf{2}^{+}$. Two long interionic Te $\cdots \mathrm{F}$ contacts (318.6(1) (F2) and 317.9(1) (F 6) pm), shorter than the van der Waals distance $\left(355 \mathrm{pm}^{[14]}\right.$ and $\left.353 \mathrm{pm}^{[15]}\right)$ are present in 3 (Fig. 1).

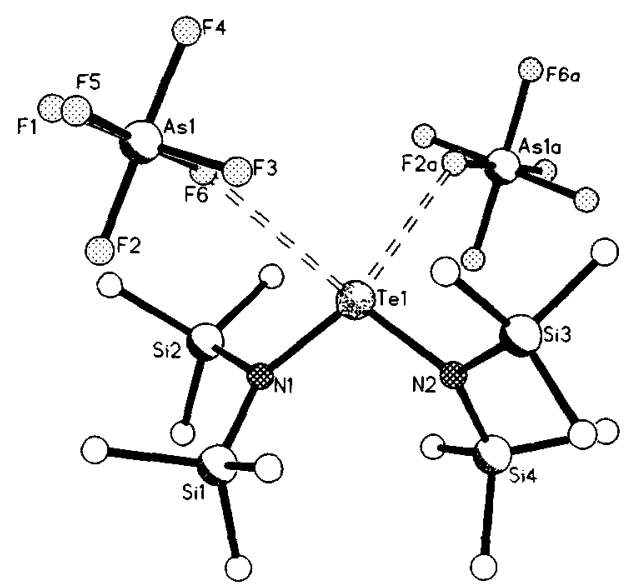

Fig. 1. Molecular structure of $2^{++}$and its nearest $\mathrm{AsF}_{6}^{-}$neighbors (hydrogen atoms have been omitted). Broken lines show relatively short interionic contacts. Important distances [pm], bond angles $\left[{ }^{\circ}\right]$, and torsional angles $\left[{ }^{\circ}\right]$ for $2^{*}$ : Te 1-N1 196.4(4), Te1-N2 196.8(4), N1-Si 1 179.5(4), N 1-Si $2180.0(4)$, N2Si 3 179.4(4), N2-Si 4 179.2(4); N 1-Te1-N 2 106.8(1), Te 1-N 1-Si 1 123.4(2), Te1-N1-Si 2 114.6(2), Te1-N2-Si 3 114.2(2), Te1-N2-Si 4 122.5(2), Si 1-N 1Si 2 120.7(2), Si3-N2-Si 4 121.3(2); N2-Te1-N1-Si 1 51.7, N2-Te1-N 1-Si 2 -141.0, N1-Te 1-N2-Si $3-139.3$, N1-Te 1-N2-Si 4 56.3. For the AsF ${ }_{6}^{-}$ion the bond distances and bond angles lie in the following ranges: As- F 165.9(5) $-169.8(4) \mathrm{pm}, \mathrm{F}-\mathrm{As}-\mathrm{F} 87.2(4)-91.5(5)^{\circ}$, respectively. The fluorine atoms are disordered in the As-F 1-F 2-F 3-F 4 plane [13].

The solution ${ }^{1} \mathrm{H}$ NMR spectrum of 3 gave a relatively broad signal $\left(\Delta v_{1 / 2}=18 \mathrm{~Hz}\right)$, as expected for a radical. Only a single broad peak $\left(\Delta \omega_{1 / 2} \approx 15 \mathrm{G}\right)$ was observed in the ESR spectrum of 3 in $\mathrm{CDCl}_{3}$, indicating a small spin density on the nitrogen atoms. Similar behavior has been observed for the isovalent pnictogen analogues of $2^{++},\left[\mathrm{P}\left(\mathrm{N}\left(\mathrm{SiMe}_{3}\right)_{2}\right)_{2}\right]^{\cdot}$ (4) and $\left[\mathrm{As}\left(\mathrm{N}\left(\mathrm{SiMe}_{3}\right)_{2}\right)_{2}\right]^{\circ}\left(5^{\circ}\right) .^{[16]}$ It was further evident from the hyperfine coupling constants of $4^{\circ}$ and $5^{\circ}$ that the single electron was localized in a p orbital on the pnictogen atoms. Similar behavior is expected for $2^{+}$. Thus, assuming an $\mathrm{AX}_{2} \mathrm{E}_{2}$ electron-pair arrangement around tellurium in $1,{ }^{[17]}$ removal of an electron from 1 would result in a rehybridization of the tellurium atom such that a pair of electrons are in a $\mathrm{sp}^{2}$ orbital and the single electron is in a p orbital. ${ }^{[18]}$

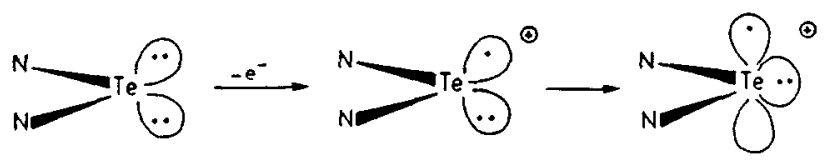

Scheme 1. Rehybridization of the tellurium orbitals on conversion of 1 to $2^{*+}$.

The bulky $\mathrm{N}\left(\mathrm{SiMe}_{3}\right)_{2}$ groups are expected to hinder the dimerization of $2^{++}$. Furthermore, $2^{++}$is stabilized by the interionic $2^{+}+\mathrm{AsF}_{6}^{-}$contacts. By contrast, dimers with relatively short $\mathrm{Te} \cdots \mathrm{Te}$ contact distances are present in the crystals of the neutral compound 1. ${ }^{[12]}$ Dimerization of $2^{\cdot+}$ is probably hindered owing to steric factors, which would reduce the energetically favorable ion-pair contacts, and electrostatic repulsion between the positively charged telluri- 
um atoms. Contact ion pairs are presumably also present in $\mathrm{CH}_{2} \mathrm{Cl}_{2}$ and $\mathrm{CHCl}_{3}$ solvents since no sharp ${ }^{19} \mathrm{~F}$ NMR resonances were observed in freshly prepared solutions of 3 . Concentrated solutions of 3 are only metastable at room temperature, however, their blue color disappearing after approximately one week.

The isolation of a $\mathrm{Te}^{\mathrm{III}}$ radical cation and the determination of its detailed geometry affords a unique opportunity for a general study of the nature of related species. Furthermore, the unexpected oxidation of 1 by $\mathrm{Ag}^{+} \mathrm{AsF}_{6}^{-}$strongly suggests that this synthetic method could be generalized to other tellurium compounds.

\section{Experimental Procedure}

All manipulations were performed under an inert atmosphere of dry nitrogen gas inside a drybox or on a glass vacuum line. The $\mathrm{CH}_{2} \mathrm{Cl}_{2}$ and $\mathrm{CHCl}_{3}$ solvents were dried over $\mathrm{P}_{4} \mathrm{O}_{10}$ and distilled and stored over molecular sieves $(4 \AA)$ prior to use. In a typical preparation, $1(1.13 \mathrm{~g}, 2.51 \mathrm{mmol})$ and $\mathrm{Ag}^{+} \mathrm{AsF}_{6}^{-}(0.74 \mathrm{~g}$, $2.50 \mathrm{mmol}$ ) were loaded into separate arms of an $\mathrm{H}$-shaped glass reaction vessel (equipped with teflon valves and a glass frit). After dissolving the compounds in $\mathrm{CH}_{2} \mathrm{Cl}_{2}(30 \mathrm{ml})$ the solutions were thoroughly mixed at $-78^{\circ} \mathrm{C}$ and the yellow solution allowed to warm to room temperature. The resulting dark blue solution was then filtered from the white-grey silver metal powder and the solvent slowly condensed off to give large black crystalline blocks of $3 .{ }^{1} \mathrm{H}$ NMR $\left(80 \mathrm{MHz}, \mathrm{CDCl}_{3},-50^{\circ} \mathrm{C}\right.$, ext. TMS $): \delta=0.45\left(\Delta v_{1 / 2}=18 \mathrm{~Hz}\right)$. ESR $\left(\mathrm{CDCl}_{3}, 10^{\circ} \mathrm{C}\right): \mathrm{g}=2.0\left(\Delta \omega_{1 / 2}=15 \mathrm{G}\right)$. UV/VIS $\left(\mathrm{CH}_{2} \mathrm{Cl}_{2}\right): \lambda_{\max }[\mathrm{nm}]=615$.

Received: March 4, 1991 [Z 4469 IE] Publication delayed at the authors' request German version: Angew. Chem. 103 (1991) 1671

CAS Registry numbers:

$1,130497-87-9 ; 3,137300-30-2 ; \mathrm{Ag}^{+} \mathrm{AsF}_{6}^{-}, 12005-82-2$

[1] G. Kirsch, L. Christiaens in S. Patai (Ed.): Chemistry of Selenium and Tellurium Compounds Vol. 2, Wiley, New York, 1987, chapter 11, pp. 421461.

[2] H. Hartl, P. Huppmann, D. Lentz, K. Seppelt, Inorg. Chem. 22 (1983) 2183.

[3] V. Betini, P. Dapporto, F. Lucchesini, A. Sega, A. De Munno, Acta Crystallogr. Sect. C 40 (1984) 653.

[4] R. Neidlein, D. Knecht, A. Gieren, C. Ruiz-Pérez, Z. Naturforsch, B 42 (1987) 84.

[5] J. S. Thrasher, J. B. Nielsen, S. G. Bott, D. J. McClure, S. A. Morris, J. L. Atwood, Inorg. Chem. 27 (1988) 570.

[6] E. Hey, C. Ergezinger, K. Dehnicke, Z. Naturforsch. B 44 (1989) 205.

[7] J. Münzenberg, M. Noltemeyer, H. W. Roesky, Chem. Ber. 122 (1989) 1915.

[8] J. P. Johnson, G. K. MacLean, J. Passmore, P. S. White, Can. J. Chem. 67 (1989) 1687.

[9] A. Haas, R. Pohl, Chimia 43 (1989) 261.

[10] H. W. Roesky, J. Münzenberg, M. Noltemeyer, Angew. Chem. 102 (1990) 73; Angew. Chem. Int. Ed. Engl. 29 (1990) 61.

[11] P. F. Kelly, A. M. Z. Slawin, D. J. Williams, J. D. Woollins, Polyhedron 9 (1990) 2659.

[12] M. Björgvinsson, H. W. Roesky, F. Pauer, D. Stalke, G. M. Sheldrick, Inorg. Chem. 29 (1990) 5140.

[13] Crystallographic data for $3\left(-120^{\circ} \mathrm{C}\right)$ : orthorhombic, $a=1137.6(2)$, $b=1253.3(2), c=1844.1(3) \mathrm{pm}, V=2.6292 \mathrm{~nm}^{3}$, space group $P 2_{1} 2_{1} 2_{1}$, $Z=4, \varrho_{c a l c d}=1.61 \mathrm{gcm}^{-3}, 3365$ unique reflections $\left[\mid F_{0}>3 \circ\left(\left|F_{0}\right|\right)\right]$, $2 \theta=8-45^{\circ}$ refined to $R=0.0261, R_{\mathrm{w}}=0.0279$. The disordered fluorine atoms $F 1-\mathrm{F} 4$ and $F 1^{\prime}-\mathrm{F} 4^{\prime}$, with $63 \%$ and $67 \%$ occupancy, respectively, were refined with identical anisotropic displacement parameters for opposite fluorine atoms. All As-F distances in the disordered plane were restrained to the same value, and a separate restraint was applied to make As-F distances perpendicular to the plane equal to one another. In addition, all $F \cdots F$ distances involving one disordered fluorine and one nondisordered fluorine were restrained to be equal. Further details of the crystal structure investigation may be obtained from the Fachinformationszentrum Karlsruhe, Gesellschaft für wissenschaftlich-technische Information mbH, W-7514 Eggenstein-Leopoldshafen 2 (FRG), on quoting the deposit number CSD-55340, the name of the authors, and the journal citation.

[14] L. Pauling: The Nature of the Chemical Bond, 3rd ed., Cornell University Press, Ithaca, NY, USA 1960, chapter 7; Die Natur der chemischen Bindung, 3rd ed., Verlag Chemie, Weinheim 1968.

[15] A. Bondi, J. Phys. Chem. 68 (1964) 441.
[16] M. J. S. Gynane, A. Hudson, M. F. Lappert, P. P. Power, H. Goldwhite, J. Chem. Soc. Dalton Trans. 1980, 2428.

[17] a) R. J. Gillespie: Molecular Geometry, van Nostrand London 1972; b) For a physical basis of VSEPR (valence shell electron pair repulsion) see R. F. Bader, R. J. Gillespie, P. J. McDougall in J. F. Liebmann, A. Greenberg (Eds.): From Atoms to Polymers: Isoelectronic Anologies, Ser. 11: VCH Publishers, New York 1989, pp. 1-51.

[18] As pointed out by one of the reviewers, an alternative rationalization would be that an electron is removed from a doubly occupied tellurium nonbonding porbital $\left(b_{2}\right)$, perpendicular to the $\mathrm{TeN}_{2}$ plane. This model is analogous to the MO description of the oxygen-atom lone pair in $\mathrm{H}_{2} \mathrm{O}$. However, for a criticism of this description see [17 b], p 32

\section{Tetrakis(dimethylamino)ethene: An Extremely Electron-Rich Molecule with Unusual Structure both in the Crystal and in the Gas Phase**}

\author{
By Hans Bock,* Horst Borrmann, Zdenek Havlas, \\ Heinz Oberhammer, ${ }^{*}$ Klaus Ruppert, and Arndt Simon*
}

\section{Dedicated to Hans Georg von Schnering} on the occasion of his 60th birthday

Which organic molecules possess such low first ionization energies that they approach those of the alkaline-metal atoms $\mathrm{Li}(5.40 \mathrm{eV})$ and $\mathrm{Na}(5.14 \mathrm{eV})$ ? Only a few answers can be given to this question and one of them is tetrakis(dimethylamino)ethene $\left(I E_{1}^{\mathrm{V}}=6.13 \mathrm{eV}^{[1, \mathrm{a}, \mathrm{b}]}\right)$. On dissolving in oxygen-free water, therefore, it forms a radical cation, presumably according to $M_{\text {solv. }}+\mathrm{H}_{\text {solv. }}^{\oplus} \rightarrow 1 / 2 \mathrm{H}_{2}+M_{\text {solv. }}^{\cdot \oplus}$ with $\mathrm{H}_{2}$ evolution. ${ }^{[\mathrm{c}]}$ Two-electron oxidation ${ }^{[1 \mathrm{~d}]}$ by halogens $\left(\mathrm{X}_{2}\right)$ yields the dication salt, the structure of which is characterized by a central $C C$ single bond of $150 \mathrm{pm}$ length and two cyanine-like molecular halves twisted relative to each other by up to $76^{\circ[1 \mathrm{e}]}[\mathrm{Eq}$. (a)].

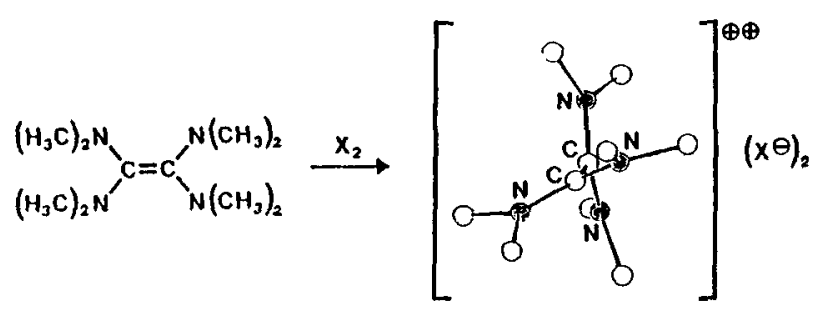

The electron richness of the readily oxidizable title compound $^{[1 \mathrm{ff}}$ is further illustrated by a comparison with the valence-isoelectronic hydrocarbon derivative, the tetraanion of tetraisopropylethene, $\left(\left(\mathrm{H}_{3} \mathrm{C}\right)_{2} \mathrm{C}^{\ominus}\right)_{2} \mathrm{C}=\mathrm{C}\left(\mathrm{C}^{\ominus}\left(\mathrm{CH}_{3}\right)_{2}\right)_{2}$, taking into consideration the different effective nuclear charges

[*] Prof. Dr. H. Bock, Dr. Z. Havlas [ ${ }^{+}$], Dipl.-Chem. K. Ruppert Institut für Anorganische Chemie der Universität Niederurseler Hang, W-6000 Frankfurt am Main 50 (FRG)

Prof. Dr. A. Simon, Dr. H. Borrmann

Max-Planck-Institut für Festkörperforschung Heisenbergstrasse 1, W-7000 Stuttgart 80 (FRG)

Prof. Dr, H. Oberhammer

Institut für Physikalische und Theoretische Chemie der Universität Auf der Morgenstelle 8, W-7400 Tübingen (FRG)

$\left[{ }^{+}\right]$Permanent address: Institute of Organic Chemistry and Biochemistry of the Czechoslovakian Academy of Sciences, Prague (CSFR)

[**] Structures of Sterically Overcrowded and Charge-Perturbed Molecules, Part 12. This work was supported by the Deutsche Forschungsgemeinschaft, the Fonds der Chemischen Industrie, and the State of Hesse. Part 11: H. Bock, GIT Fachz. Lab, 35 (1991) 557 